\title{
Investigating detailed impacts of climate change on flood inundation: a case-study from Tasmania
}

\author{
K.A.S. Brown ${ }^{1}$, F.L.N. Ling ${ }^{1}$, K.A. Robinson ${ }^{1}$, C.J. White ${ }^{2,3}$, J. Peterson ${ }^{1}$, and N. West ${ }^{1}$ \\ ${ }^{I}$ Entura, 89 Cambridge Park Drive, Cambridge TAS 7170, AUSTRALIA \\ ${ }^{2}$ Antarctic Climate \& Ecosystems Cooperative Research Centre (ACE CRC), Hobart TAS 7001, AUSTRALIA \\ ${ }^{3}$ Queensland Climate Change Centre of Excellence (QCCCE), BRISBANE QLD 4001, AUSTRALIA \\ Email: fiona.ling@entura.com.au
}

\begin{abstract}
The impacts of climate change on flooding in Tasmania have not previously been subject to detailed research. In this study, design rainfall outputs generated from an ensemble of six fine-scale regional climate models by the Climate Futures for Tasmania project were used to assess impacts on flood extent for four large Tasmanian rivers for the SRES A2 emissions scenario.
\end{abstract}

Current design rainfalls were obtained using either focused rainfall growth estimate technique (FORGE) or Australian Rainfall and Runoff (ARR). Climate Futures for Tasmania gridded rainfall data was used to derive catchment wide percentage change in design rainfall depth for the 1 in 10, 1 in 50, 1 in 100 and 1 in 200 Annual Exceedance Probability (AEP) storm events for durations of 24, 48 and 72 hours. Changes in design rainfalls for these durations were used to extrapolate design rainfalls for durations of 12 and 18 hours.

Hydrographs were developed for four catchments: the Derwent River, the Forth River, the Huon River and the Mersey River. Catchment areas and sub areas for each of the rivers were obtained from previous studies undertaken for Hydro Tasmania. Rainfall-runoff routing models, the routing network, routing parameters and the loss parameters for each of the models were sourced from previous flood studies for each of the four rivers. Preexisting hydrological models developed for Hydro Tasmania to model dam break floods (Smythe (1995, 2001a, 2001b), Knight (2007)). were modified for use in modelling the 1 in 10, 1 in 50, 1 in 100 and 1 in 200 AEP events for the baseline period (1961-1990) and future periods (2010-2039, 2040-2069 and 2070-2099). The critical durations of the floods were determined for each AEP.

Projected future flood hydrographs were used as inputs to hydraulic models of the river downstream of the damsites. Existing flood hydraulic models were run for each of the selected catchments and each of the design floods under baseline and future climate periods.

Flood extents increased under climate change for all rivers with the exception of the Derwent River. The critical duration of design rainfall for the Derwent River at the point of interest was 72 hours. This study found that climate change will substantially increase the intensity of shorter duration rainfall events, but will only have a limited impact on the intensity of rainfall events with durations in excess of 24 hours.

Keywords: Climate Change, Flood, Hydrology, Dynamical Downscaling. 


\section{INTRODUCTION}

A series of flood inundation maps were produced for four catchments in Tasmania using projected proportional changes applied to design rainfalls estimated using the Tasmanian application of the Focused Rainfall Growth Estimation (FORGE) technique (Gamble and McConachy, 1999) and Australian Rainfall and Runoff (ARR, Engineers Australia, 1999). The study was undertaken for the State Emergency Service (SES) as part of the Climate Futures for Tasmania (CFT) project, and will provide valuable information on the future trend of flooding impacts as a result of projected changes to the climate. A focus of CFT was to determine possible changes to climatic extreme events resulting from climate change to the end of the $21^{\text {st }}$ Century.

This paper focuses on the method used to produce a series of flood maps which showcase how flood extents are likely to change between the baseline period and the end of the 21 st century. The catchments modelled in this study were those of the Derwent River, Forth River, Huon River and the Mersey River (Figure 1). All four rivers modelled flow through populated centres and are of direct interest to the SES. The impact of climate change on the intensity, duration, magnitude and extent of flood events across these four catchments was investigated.

\section{CHANGES TO DESIGN RAINFALLS}

Design rainfalls for annual exceedance probabilities (AEPs) of 1:10, 1:50, 1:100 and 1:200 for baseline and future climate were sourced from the Climate Futures for Tasmania (CFT) project. CFT was an interdisciplinary and multi-institutional collaboration of twelve core participating partners from both state and national organizations. This project generated high-resolution climate change projections for Tasmania. Dynamical downscaling was used to generate climate projections over Tasmania at a resolution of $0.1^{\circ}$ (Corney et.al. 2010). Six of the 23 Global Climate Models (GCMs) reported on in the IPCC Fourth Assessment Report (IPCC, 2007) were selected for downscaling under SRES A2 scenario. The dynamical downscaling procedure was used to produce gridded climate data over Tasmania, including daily rainfall at each grid point for the period 1960-2100.

A focus of CFT was to investigate possible changes to climatic extreme events resulting from climate change to the end of the 21st Century. Changes to the frequency,

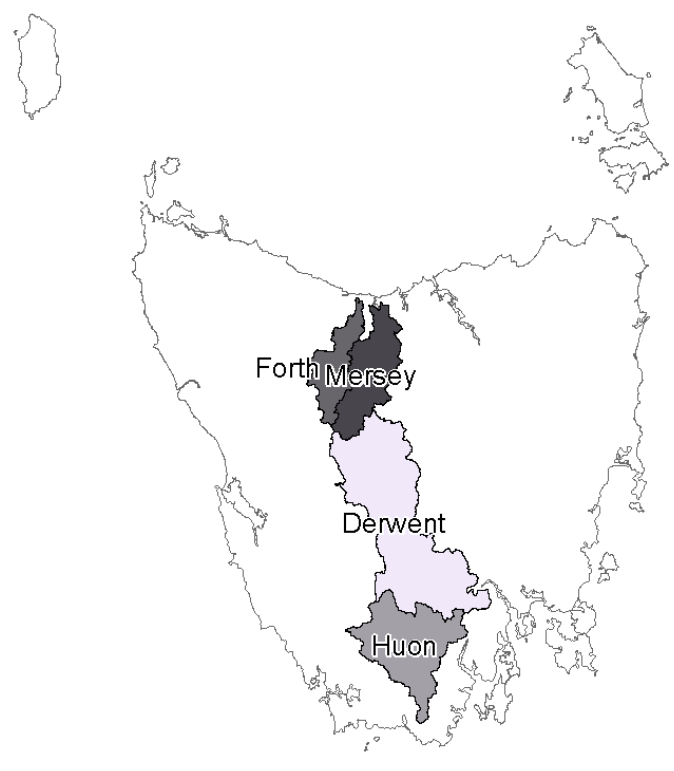
magnitude and duration of extreme events due to changes

Figure 1. Catchments modelled in this study. in the global climate as a result of the enhanced greenhouse effect were assessed using the downscaled datasets. White et al. (2010) applied an automated generalised Pareto distribution (GPD) fitting procedure to the daily rainfalls from the downscaled projections for a baseline period, 1961-1990, and three future periods, 2010-2039, 2040-2069 and 2070-2099, for rainfall durations of 24 hours, 48 hours and 72 hours. Multi-GCM ensemble simulations were found to provide more robust information than simulations from any single model (Meehl et al., 2007). White et al. (2010) concatenated the rainfall timeseries from the ensemble of six climate simulations to increase the number of rainfall events available for the fitting procedure to 180 years (six models x 30 years) for each time slice.

White et al. (2010) assessed the ability of the downscaled GCMs to simulate extreme rainfalls against gridded observations by applying the GPD fitting procedure to the rainfalls available from the Australian water availability project (AWAP) (Jones et al. 2009) dataset for 1961-1990. White et al. (2010) showed that 1:200 rainfalls calculated from AWAP had very similar spatial patterns to 1:200 AEP rainfalls calculated from the ensemble of downscaled GCMs. However, the magnitudes of 1:200 AEP rainfalls calculated from the downscaled GCMs differed by up to $\pm 60 \%$ from those calculated from AWAP. Because of these biases, we applied percent changes calculated from changes in extreme rainfalls to design rainfalls calculated using established techniques.

Projected changes are not uniform across the three future periods of 2010-2039, 2040-2069 and 2070-2099, and the modelling shows that some areas would actually see a decrease in rainfall intensity for a given AEP in the 
latter part of the 21 st century when compared against the 2040-2069 period (White et al., 2010). Table 1 shows the variability in projected changes across the three future periods. For example, Miena/Liawenee in the Central Highlands shows a marked reduction in projected precipitation during the middle part of the century (2040-2069) compared against the end of the century (2070-2099). It should be noted that this is consistent with the relatively large projected decline in annual precipitation over the central highlands (White et al., 2010).

Table 1. Magnitude of the 24-hour duration 1:200 AEP for 1961-1990 estimated from AWAP observations $\left(5^{\text {th }} / 95^{\text {th }}\right.$ CIs in brackets), with projected multi-GCM ensemble change for 2010-2039, 2040-2069, 2070-2099, at five representative locations across Tasmania. AEPs estimated using a generalised Pareto distribution.

Multi-GCM ensemble AEPs estimated using the ensemble of six downscaled GCMs for SRES A2. ARIs are expressed in $\mathrm{mm}$. Changes are expressed in $\mathrm{mm}$ and as a percentage change (in brackets), relative to the 1961-1990 baseline (White et al., 2010).

\begin{tabular}{|l|l|l|l|l|}
\hline Location & $\begin{array}{l}\text { ARI-200 } \\
(\mathbf{m m})\end{array}$ & $\begin{array}{l}\text { Multi-GCM } \\
\text { ensemble } \\
\mathbf{( 2 0 1 0 - 2 0 3 9 )}\end{array}$ & $\begin{array}{l}\text { Multi-GCM } \\
\text { ensemble } \\
\mathbf{( 2 0 4 0 - 2 0 6 9 )}\end{array}$ & $\begin{array}{l}\text { Multi-GCM } \\
\text { ensemble } \\
\mathbf{( 2 0 7 0 - 2 0 9 9 )}\end{array}$ \\
\hline Hobart & $100(76 / 128)$ & $31[31 \%]$ & $40[40 \%]$ & $30[30 \%]$ \\
\hline Launceston & $66(51 / 85)$ & $3[4 \%]$ & $34[51 \%]$ & $34[52 \%]$ \\
\hline Devonport & $97(76 / 131)$ & $4[4 \%]$ & $23[24 \%]$ & $36[37 \%]$ \\
\hline Strathgordon & $97(93 / 105)$ & $21[21 \%]$ & $30[31 \%]$ & $36[37 \%]$ \\
\hline Miena/Liawanee & $98(78 / 134)$ & $50[51 \%]$ & $30[30 \%]$ & $5[5 \%]$ \\
\hline
\end{tabular}

Design rainfall depths did not show a consistent increase for the 21 st century (Table 1). It is likely that this is caused by natural variability swamping the climate signal in the earlier part of the century. The climate signal-tonoise ratio is likely to be greatest at the end of the century. In order to better isolate the impacts of climate change on design rainfalls from natural variability, the percentage change in rainfalls from the baseline period to the end of the 21st century (2070-2099) was linearly scaled back to obtain changes for the intermediate periods. This method has the effect of producing a conservative (greater) climate impact on the design rainfall for the period 2010-2069.

\section{HYDROLOGICAL MODELLING}

The average percentage change in design rainfalls between the baseline period and the three future periods was calculated for each catchment, for each AEP and for each rainfall duration. Design rainfalls derived using ARR99 and FORGE (Focused Rainfall Growth Estimation, Nandakumar et al., 1997, Gamble and McConachy, 1999) were multiplied by this percent change.

The design precipitation depths for one catchment are summarised in Table 2. Colour coding has been used to identify the various subsets that make up the overall design precipitation and the methodologies attributed to these subsets. 
Table 2. Adopted Design Precipitation for the Forth catchment (mm).

\begin{tabular}{l|l|l|l|l|l|l|l|l|l|l|l|l}
\hline & \multicolumn{3}{|c}{$1961-1990$} & \multicolumn{3}{c|}{$2010-2039$} & \multicolumn{2}{c}{ 2040-2069 } & \multicolumn{3}{c}{$2070-2099$} \\
\hline AEP (1:Y) & $\mathbf{2 4}$ & $\mathbf{4 8}$ & $\mathbf{7 2}$ & $\mathbf{2 4}$ & $\mathbf{4 8}$ & $\mathbf{7 2}$ & $\mathbf{2 4}$ & $\mathbf{4 8}$ & $\mathbf{7 2}$ & $\mathbf{2 4}$ & $\mathbf{4 8}$ & $\mathbf{7 2}$ \\
\hline $\mathbf{1 0}$ & 107 & 137 & 155 & 112 & 139 & 158 & 118 & 141 & 161 & 123 & 143 & 164 \\
\hline $\mathbf{5 0}$ & 144 & 185 & 210 & 153 & 187 & 215 & 162 & 189 & 219 & 171 & 191 & 223 \\
\hline $\mathbf{1 0 0}$ & 160 & 208 & 239 & 171 & 210 & 244 & 182 & 212 & 248 & 192 & 214 & 253 \\
\hline $\mathbf{2 0 0}$ & 178 & 234 & 270 & 191 & 236 & 275 & 204 & 238 & 280 & 216 & 241 & 285 \\
\hline
\end{tabular}

Blue Standard Forge Precipitation

Green ARR99 Precipitation factored up to fit Forge Precipitation Curve

Red CFT Percentage Change in Precipitation applied to 1961-1990 Adopted Design Precipitation

\subsection{Hydrologic Models}

Pre-existing rainfall-runoff models with streamflow routing, developed by Hydro Tasmania (Smythe (1995, 2001a, 2001b)) to model dam break floods, were modified to generate hydrographs for the 1:10, 1:50, 1:100 and 1:200 AEP events. All model parameters were calibrated to the baseline period. No further variation to model parameters was made.

\subsection{Critical Duration Analysis}

Critical durations were analysed for the four catchments. This analysis was undertaken with the aim of identifying the critical duration storm event and to determine whether the critical duration would be likely to change as a result of climate change. Previous studies provided indications of the critical duration event for inflows and outflows to major storages in each of the catchments for the baseline period of 1961-1990, shown in Table 3.

Critical durations for Derwent River outflows and inflows were 120 hours for all AEPs. At longer durations design rainfalls were not available, thus the critical duration may exceed 120 hours.

Analysis of the Mersey River for the baseline period shows that the catchment has a critical duration of 24 hours. However, for the 2010-2039 period the critical duration is 18 hours, with the exception of the $1: 10$ AEP which remains at 24 hours. For the 2040-2069 and 2070-2099 periods the critical durations for all AEPs were found to be 18 hours. This finding is supported by the distribution of percentage change in rainfall which indicates that climate change will

Table 3. Critical Outflow and Inflow Durations for the four catchments.

\begin{tabular}{l|l|l}
\hline \multicolumn{1}{c|}{ Catchment } & $\begin{array}{c}\text { Critical Outflow } \\
\text { Duration }\end{array}$ & $\begin{array}{c}\text { Critical Inflow } \\
\text { Duration }\end{array}$ \\
\hline Forth & 24 hours & 24 hours \\
\hline Mersey & $24 / 18$ hours & $24 / 18$ hours \\
\hline Derwent & $120+$ hours & $120+$ hours \\
\hline Huon & 24 hours & 24 hours \\
\hline
\end{tabular}
substantially increase the intensity of shorter duration rainfall events, and conversely will show only a limited impact on the intensity of rainfall events with durations in excess of 24 hours. Figure 3 below shows percentage change in the outflow flood between the baseline and the end of the 21st century (2070-2099). 


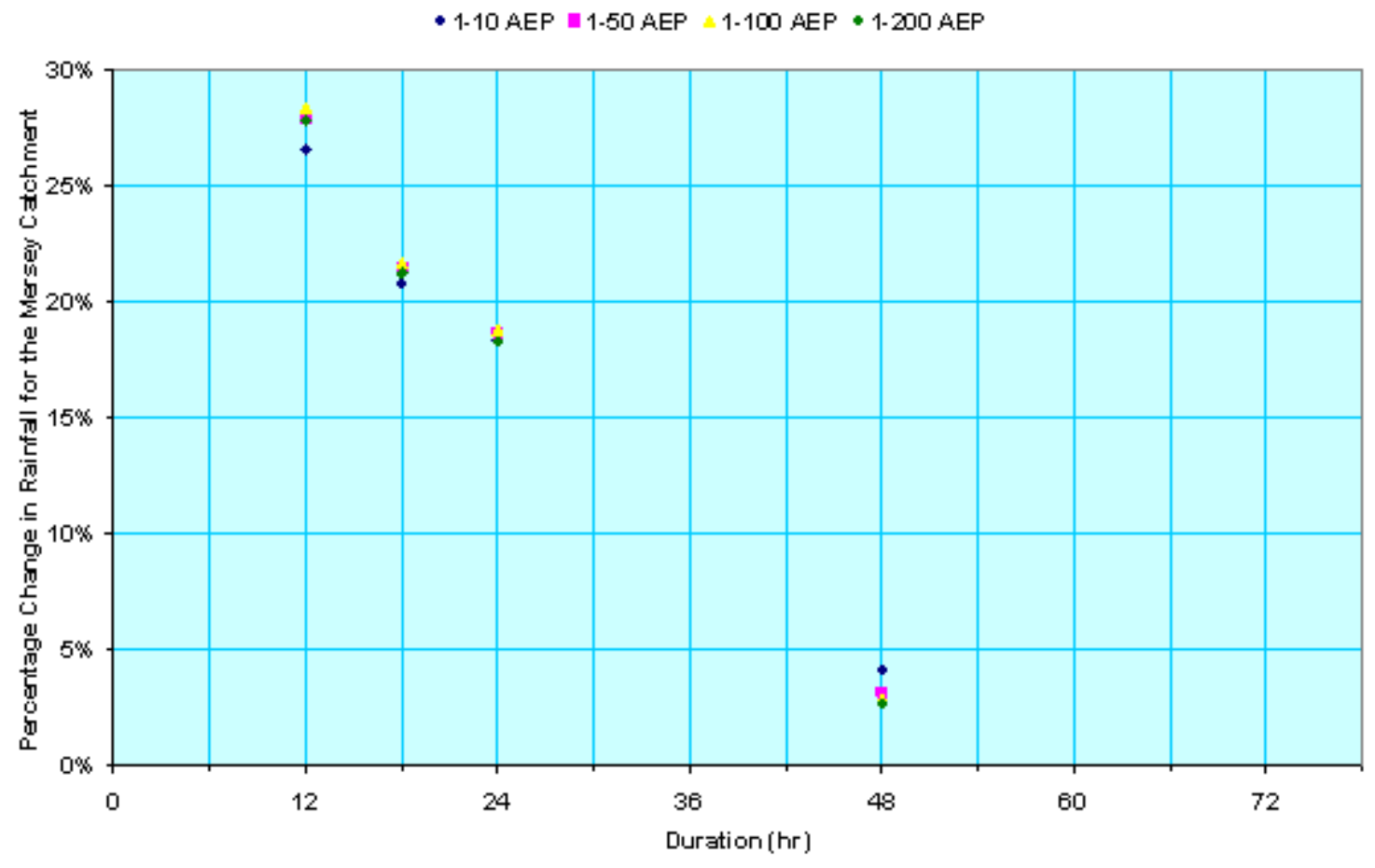

Figure 2. Percentage change in precipitation depth between 2070-2099 and the baseline period for the Forth River.

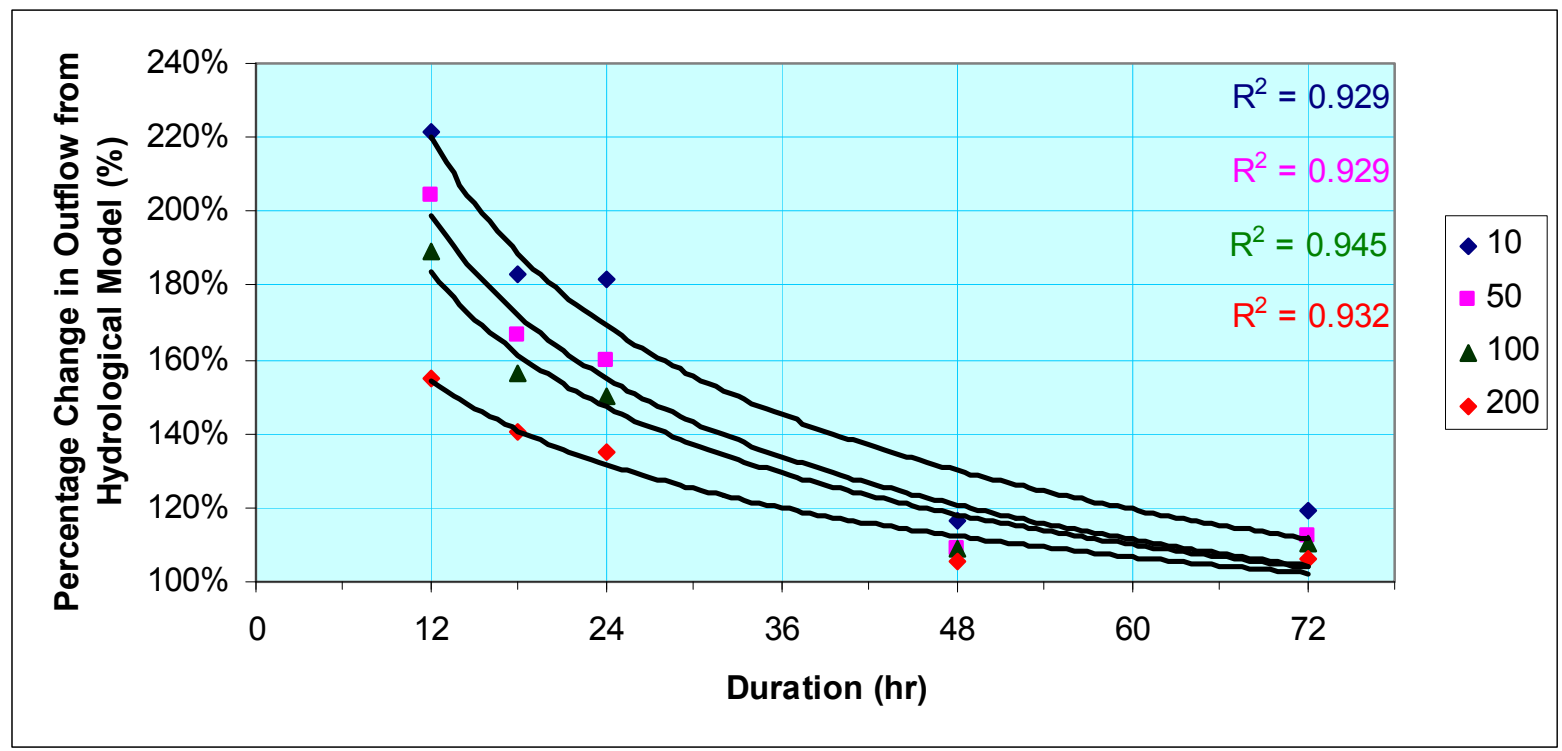

Figure 3. Percentage change in the outflow flood for the Forth catchment between 2070-2099 and the baseline period.

Prior to this study, flood mapping on these catchments had not investigated storm events with durations greater than 72 hours as no design rainfall data was available. However, the 96 hour and 120 hour design rainfalls are now available from the FORGE analysis. Where catchments have been found to have a critical duration of greater than 72 hours, the percentage change in design rainfall intensity is small and is anticipated to be within the error bounds of the modelling. 
The following conclusions have been drawn based on the above study.

(i) Catchments which have a critical duration of greater than 72 hours are unlikely to see any significant increases in precipitation as a result of climate change and as such it can be assumed that the critical duration will remain stationary.

(ii)

Catchments with a critical duration less than 72 hours will see increases in precipitation and as such the critical duration will be more likely to lessen.

\section{HYDRAULIC MODELLING}

Pre-existing 1 dimensional and 2 dimensional hydraulic models were used to generate flood levels over the areas of interest. Whilst it is recognised that storm-surge is likely to result in increased inundation risk for coastal areas, storm surge has not been taken into consideration for this study, as this study is investigating the impacts of changes in the intensity, frequency and duration of precipitation events not on storm surge.

Sea level rise was incorporated into the hydraulic models. This study has assumed a $0.8 \mathrm{~m}$ rise in sea level by the end of the 21st century. The Intergovernmental Panel on Climate Change (IPCC) reported that the upper limit of sea level rise is projected to be $0.8 \mathrm{~m}$ by 2100 (IPCC, 2007). This estimate is inclusive of a provision of $0.2 \mathrm{~m}$ to take into account the projected extent of ice sheet melt to that time. On the basis of these projections and in the absence of national benchmarks for coastal vulnerability, both the Victoria Coastal Council (2008) and Queensland Department of Environment and Resource Management (2009) have established policies of planning for sea level rise of not less than 0.8 meters by 2100 . In the absence of further information, this study has applied a $0.8 \mathrm{~m}$ sea level rise to each of the periods under review with the exception of the baseline period.

Results from the hydraulic modelling indicate that changes to the maximum water depths during flood events will be proportional to the change in inflow. Figure 3 shows the percentage change in flood levels associated with the 1:100 AEP flood event between the baseline period and the end of the $21 \mathrm{st}$ century. The furthest downstream chainages are clearly impacted by sea level rise as can be seen in Figure 4.

\section{GIS MAPPING}

Results from the hydraulic modelling were used to generate flood inundation maps for the four catchments of interest for use by State Emergency Services (SES). An example of these maps is shown in Figure 5. The maps included flood extents for all AEPs of interest for the three future periods.

\section{RESULTS}

Through the undertaking of a critical duration analysis for the four catchments, it has been found that catchments that have significant upstream storages and critical durations of 72 hours or greater are unlikely to be significantly impacted by climate change impacts. Conversely, the intensity of short duration events is likely to increase. It is recommended that efforts to gauge the impact of climate change on flood inundation should be focused on catchments which have minimal upstream storages and have critical durations less than 72 hours.

Flood levels are shown to be impacted predominately by changes in the design rainfall for upstream chainages. However, downstream sites are more significantly impacted by the anticipated rise in sea level at the end of the 21 st century.

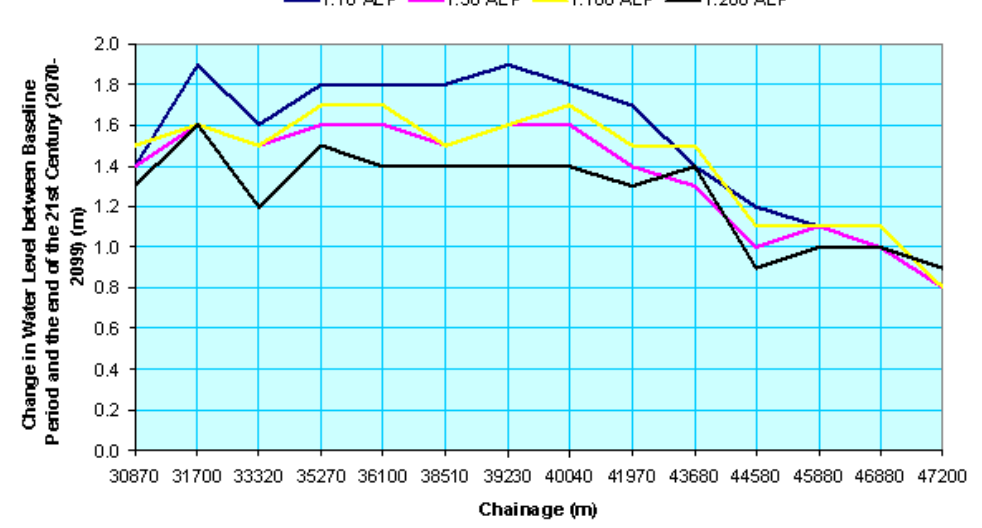

Figure 4. Change in Maximum Flood Level between 2070-2099 and the 1961-1990 baseline period. 


\section{CONCLUSIONS}

Inundation maps developed during this study have shown that climate change impacts on flood inundation can be captured at the local and regional scale using design rainfalls generated by high resolution dynamical downscaling of GCMs.

Projected flood levels increased proportionally more than rainfall depths. For catchments with critical durations greater than 72 hours or with significant upstream storages climate change impacts on flood inundation appear to be insignificant. The intensity and frequency of duration events less than 72 hours were found to increase significantly by the end of the century.

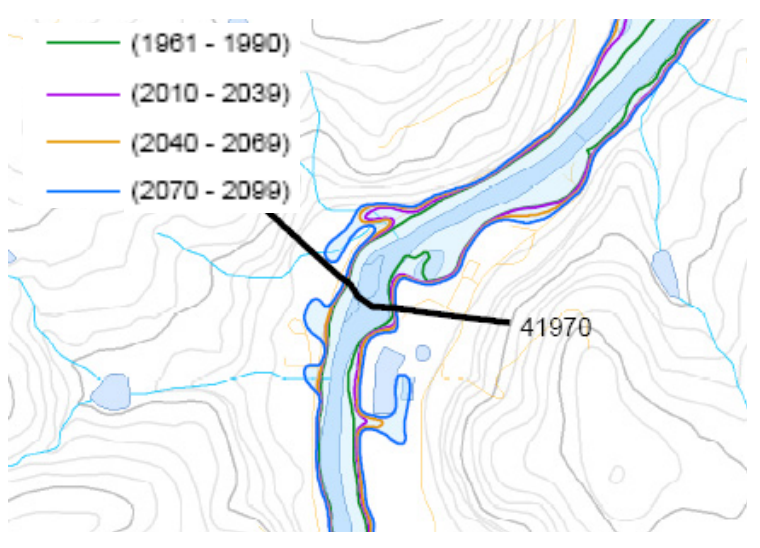

Figure 5. Example of change to inundation levels for $1: 10$ flood as a result of climate change.

\section{ACKNOWLEDGMENTS}

This work was conducted in collaboration with Climate Futures for Tasmania and SES Tasmania.

\section{REFERENCES}

Corney, S., Katzfey, J.J., McGregor, J.L., Grose, M., Bennett, J., White, C.J., Holz, G., and Bindoff, N.L. (2010) Climate Futures for Tasmania: climate modelling technical report, Antarctic Climate \& Ecosystems Cooperative Research Centre, Hobart, Tasmania.

Department of Environment and Resource Management (2009) Draft State Planning Policy Coastal Protection. The Queensland Government, Brisbane, Queensland.

Gamble, S. and McConachy, F., (1999) Application of the Focussed Rainfall Growth Estimation Technique in Tasmania. Proceedings of Water99 Joint Congress, pp. 691-696, Brisbane, 6-8 July 1999. Inst. Engrs. Aust.

IPCC (Intergovernmental Panel on Climate Change) (2007). Summary for Policy Makers. In: Climate Change 2007: Impacts, Adaptation and Vulnerability. Contribution of Working Group II to the Fourth Assessment Report (AR4) of the Intergovernmental Panel on Climate Change [Parry, M.L., O.F., Canziani, J.P. Palutikof, P.J. van der Linden and C.E. Hanson, (eds.)]. Cambridge University Press, Cambridge, UK, and New York, pp 7-22. Available at http://www.ipcc.ch.

Jones, D.A., Wang, W. and Fawcett, R. (2009) 'High-quality spatial climate data-sets for Australia', Australian Meteorological and Oceanographic Journal, 58: 233-248.

Knight, J., (2007) Huon Flood Evacuation Plan, Hydro Tasmania Consulting Report Engagement Number.: E201709-Report-01

Meehl, G.A., Stocker, T.F., Collins, W.D. , Friedlingstein, P., Gaye, A.T., Gregory, J.M., Kitoh, A., Nutti, R., Murphy, J.M., Noda, A., Raper, S.C.B., Watterson, I.G., Weaver, A.J. and Zhao, Z-C. (2007) 'Global Climate Projections' in: Climate Change 2007: The Physical Science Basis. Contribution of Working Group I to the Fourth Assessment Report of the Intergovernmental Panel on Climate Change. S. Solomon, D. Qin, M. Manning et al Cambridge, United Kingdom, Cambridge University Press.

Nandakumar, N., Weinmann, P.E., Mein, R.G. and Nathan, R.J. (1997) Estimation of Extreme Rainfalls. Using the CRC-FORGE Method (For Rainfall Durations 24 to 72 Hours), Report 97/4.

Smythe, C. (1995) Review of the Spillway Design Flood for Paloona Dam, Hydro-Electric Commission Consulting Business Unit Water Resources Department Report No.: ENE-0004-30-01-CR-003

Smythe, C. (2001a) HEC Portfolio Risk Analysis: Hydrology - Spillway Re-assessment for Wilmot, Paloona, Mackenzie, Liapootah, Wayatinah and Meadowbank

Smythe, C. (2001b) Review of the Flood Hydrology for Parangana, Rowallan and Mackenzie Dams, Hydro Tasmania Report No.: GEN-0309-CR-003.

Victorian Coastal Council (2008) Victorian Coastal Strategy. Victorian Coastal Council, Melbourne, Victoria.

White, C.J., Sanabria, L.A., Grose, M., Corney, S.P., Bennett, J.C., Holz, G.K., McInnes, K.L., Cechet, R.P., Gaynor, S.M., and Bindoff, N.L. (2010) Climate Futures for Tasmania: extreme events technical report, Antarctic Climate \& Ecosystems Cooperative Research Centre, Hobart, Tasmania. 